\title{
Increasing Serum Cholesterol Level among Sri Lankan Adult Obese Patients Admitted to Medical Wards: A Cross-sectional Study
}

\author{
R. (II) P. DIOSO ${ }^{1 *}$, K. SHALINA ${ }^{2}$ AND K. JUDENIMAL ${ }^{3}$
}

\begin{abstract}
This research identified the factors affecting the widespread of the level of serum cholesterol among adult obese patients admitted to government hospitals in the eastern part of Sri Lanka, and identified the number of adults obese patients with increasing serum cholesterol level. A descriptive crosssectional study design was used. Convenience sampling technique helped select 150 patients in medical wards and clinics of two government hospitals in the eastern province of Sri Lanka, and Questionnaires were distributed for data analysis. Overall findings of 150 obese patients regarding increasing serum cholesterol level admitted in the medical wards and follow-up at medical clinics had $59 \%$ in moderate risk, $36 \%$ with high risk, and $2 \%$ with a minimal risk of increasing serum cholesterol level. Gender was a factor, which brings about $49.3 \%(n=74)$ of the respondents were female and $50.7 \%(n=76)$ were male. About $59 \%$ of participants had $130-159 \mathrm{mg} / \mathrm{dl}$ of total cholesterol level while $36 \%$ had $160-189 \mathrm{mg} / \mathrm{dl}$ and $1 \%$ had lower than $100 \mathrm{mg} / \mathrm{dl}$. It was also identified that age and co-morbidities of obesity are factors that affect an increasing serum cholesterol level.
\end{abstract}

Key words: Cross-sectional study; increasing serum cholesterol; obesity; medical nursing

This study is the first observational study report on an increasing serum cholesterol level among adult obese patients admitted to two government hospitals in the eastern part of Sri Lanka.

One of the most essential functions of the serum cholesterol is to serve as the primary raw material from which your body makes many major steroid hormones, including testosterone, estrogen, progesterone, cortisone, and aldosterone (Basavanthappa, 2005; Roberta et al. 2006). Without cortisone your body could not cope with stress, and without aldosterone, your body could not properly balance your sodium and water levels (Basavanthappa 2005; Roberta et al. 2006).

Age, gender, and genetics are the factors that cannot control the elevating serum cholesterol level but, diet and lifestyle can control the elevating serum cholesterol level (Cordelia \& Milliard 1995). Also lack of proper knowledge regarding the importance of maintaining optimal serum cholesterol level, negligence of health advice and no willingness to change their life style and diet patterns are the reasons for increasing their serum cholesterol level (Office of Medicine Application Research 1985).

\footnotetext{
${ }^{1}$ Faculty of Nursing, Lincoln University College, Jalan SS 6/12, 47301 Petaling Jaya, Malaysia

2 Ashraff Memorial Hospital, Sri Lanka

${ }^{3}$ Batticaloa Teaching Hospital, Sri Lanka

* Corresponding author (e-mail: duke@lincoln.edu.my)
} 
Most obese patients perceive that anticholesterol drugs can reduce the serum cholesterol level rather the dietary control and lifestyle modification (Cordelia \& Milliard 1995; Roberta et al. 2006). When patients are affected by increasing serum cholesterol level, they are admitted to hospitals and get complications such as cardiovascular diseases, stress, and neurological disorders which are co-morbidities of obesity (Turley \& Dietschy 1988; Cordelia \& Milliard 1995).

\section{Problem Statements}

Elevating serum cholesterol level is one of the main causes of mortality in Sri Lanka. In spite of many awareness programs and free health services for the public, hospital statistics reported that a number of admission with high serum cholesterol and its complications are getting high.

\section{Hypotheses}

There are significant evidence of an increased serum cholesterol level among adult obese patients admitted to medical wards in the eastern part of Sri Lanka.

\section{Variables}

The cause variable is obesity, and the effect variable is the increasing serum cholesterol level. The variables will answer the question, "Are there statistical evidences on the increasing serum cholesterol level among adult obese patients admitted to government hospital in the eastern part of Sri Lanka?"

\section{Objectives}

At the end of this research, it is hoped to:

(1) Identify the factors that affect an increasing level of serum cholesterol among adult obese patients admitted to medical wards; and

(2) Distinguish the prevalence of adult obese patients with increasing serum cholesterol level.

\section{LITERATURE REVIEW}

Articles were extracted from Google Scholar, and PubMed search engines using the combination of following key words: "increasing serum cholesterol level, adult obese patients and obesity".

\section{Sources}

Sources of literature usually used in research studies are of scientific researches (Turnock 2004; Burns \& Grove 2007; Indrani 2005). There were adequate research articles related to this topic but not in the Sri Lankan context. The researchers found literature from other countries related to this subject. There were few research articles available during the past five years. Therefore, articles up to ten years back were used.

\section{Critical Appraisal}

Arai et al. (1994) investigated the "Increased plasma cholesterol ester transfer protein in obese subjects". In this research the mechanism for this reduction has not been fully clarified. Cholesteryl ester transports protein (CETP) transfers cholesterol ester from HDL to apolipoprotein B-containing lipoproteins and plays a major role in regulating the concentration and composition of HDL. The CETP, and postheparin lipoprotein lipase (LPL) and hepatic triglyceride lipase (HTGL) investigated activities in 30 obese subjects (17 women and 13 men, age $44 \pm 14$ years, mean \pm SD). The average body mass index 
of the obese subjects was $33.1 \pm 4.8 \mathrm{~kg} /$ $\mathrm{m}^{2}$ (range, 26.4 to $43.8 \mathrm{~kg} / \mathrm{m} 2$ ). The obese subjects showed significantly lower serum HDL cholesterol levels than control subjects $(1.04 \pm 0.28$ versus $1.50 \pm 0.34 \mathrm{mmol} / \mathrm{l}, \mathrm{P}<0.01)$. In the obese subjects, both activities and protein mass of CETP and postheparin HTGL activities were significantly increased,whereas postheparin LPL activities were significantly decreased. CETP activities, independent of postheparin HTGL and LPL activities, were correlated negatively with HDL-cholesterol $(\mathrm{r}=-0.39, \mathrm{P}<0.05)$. And the cholesteryl ester to triglyceride ratio of HDL2 and HDLj $(\mathrm{r}=-0.36, \mathrm{P}<0.05 ; \mathrm{r}=-\mathrm{M}, \mathrm{P}<0.05$, respectively). CETP activities were correlated positively with body mass index $(\mathrm{r}=0.38, \mathrm{P}<0.05)$, body fat ratio $(\mathrm{r}=0.42, \mathrm{P}<0.05)$, and subcutaneous fat area determined by abdominal CT scan imaging $(\mathrm{r}=0.49, \mathrm{P}<0.05)$ and negatively with visceral fat/subcutaneous fat ratio $(r=-0.52$, $\mathrm{P}<0.01$ ). After body weight reduction by caloric restriction, both activities and protein mass of CETP were reduced. These results suggest that high levels of plasma CETP may partly explain the decrease of serum HDL cholesterol in obese subjects and that plasma CETP levels may be regulated by the degree of total body fat accumulation.

Hill and Peters (2010) evaluated the current epidemic of obesity that is caused largely by an environment that promotes excessive food intake and discourages physical activity. Although humans have evolved excellent physiological mechanisms to protect against body weight loss, they have only weak physiological mechanisms to defend against body weight gain when food is abundant. Control of portion size, consumption of a diet low in fat and energy density, and regular physical activity are behaviours that protect against obesity, but it is becoming difficult to adopt and maintain these behaviours in the current environment. On account of obesity is difficult to treat, public health efforts need to be directed toward prevention. According to the Hill and Peters (2010), the relationship between certain diets and serum cholesterol levels, are the effect of obesity. Thus, a lot of obese patients have high serum cholesterol levels and risk of heart diseases.

\section{Analysis}

While all these studies were carried out in other countries, Sri Lankan literature was not available to bring definitions to obesity. The articles above are appropriate. From 1994 to 2010 , the difference between the years would give the foundation to the operational definitions in this study.

According to the literatures reviewed, obese patients are defined as, persons who are more than overweight or are undergoing treatment for high cholesterol (Aria et al. 1994; Hill \& Peters 2010). On the other hand, cholesterol is defined as, a byproduct of obesity made by the liver and acquired through diet (Hill \& Peters 2010; Aria et al. 1994). The body uses cholesterol to produce bile, some hormones, vitamin D, cell membrane and myelin (Aria et al. 1994; Hill and Peters, 2010). High blood cholesterol has been linked to a lot of diseases and is believed to be the cause of mortality over 10 years' time (Aria et al. 1994; Hill \& Peters 2010). An increasing serum cholesterol level among adult obese patients must be observed.

\section{METHODOLOGY}

Research methodology is a way to solve the research problem systematically. It may be understood as a science of studying how 
research is done scientifically (Polit \& Beck 2013). This section will describe the design, sampling techniques, and the method of data collection.

\section{Research Design}

This study planned to conduct using a descriptive cross-sectional design since two government hospitals will be used to select the respondents. It is more appropriate to investigate two hospitals admitting adult obese patients with increasing serum cholesterol level to identify prevalences from two sections.

\section{Research Setting}

Specifically, the researchers conducted their study at Ashraff memorial hospital and Kalmunai base hospital.

\section{Population and Sampling}

Convenience sampling technique was used to select the respondents. The accessible populations were patients who had more than $240 \mathrm{mg} / \mathrm{dl}$ serum cholesterol level between the age group 35 years to 60 years. This study used 150 patients with increasing serum cholesterol level during the month of April to October 2016.

The sample size was calculated using this formula:

$$
\begin{gathered}
\mathrm{n}=\frac{Z^{2} \cdot P(1-P)}{d} \\
\text { where } \mathrm{n}=\text { Population; } \\
\mathrm{z}=\text { Confidence; } \\
\mathrm{p}=\text { Prevalence; } \\
\mathrm{d}=\text { Precision. }
\end{gathered}
$$

\section{Data Collection}

All adequate information were given to all the participants regarding the study and,invited them to participate. Data collection in this study was done using a questionnaire. A questionnaire was in a printed paper to elicit information that can be obtained through written response of the patients. The close-ended questionnaire became appropriate as an umbrella to answer the objectives and hypotheses set (Cormack 1996).

Distributing the questionnaires was conducted from April to September 2016. Data was collected from 150 of patients with high serum cholesterol. Questionnaire completed at the same place. The questionnaire was initially developed in English and it was translated in to both Tamil and Sinhala language to cover up all ethnic groups to ensure that all participants understood the questionnaire without any difficulty. The rate of response of this study was $100 \%$. Questions were sets of multiple choices, and the respondents would only tick one answer from the given selections.

\section{Data Analysis}

Data processing and analysis were done using descriptive statistics and software summarized data were presented in appropriate charts and tables using manual and SPSS version 21. This study analyzed all responses made by patients, with the help of computer guided graphs and charts to understand their perception on increasing serum cholesterol level.

The population and estimated prevalence are set at $20 \%$ because the margin of error was at $5 \%$ precision with the confidence of $95 \%$. Central tendencies with probability findings were used to mathematically analyze the data collected.

\section{Ethical Permission}

Ethics refers to the quality of research procedures to their adherence to professional, 
legal and social obligations to research subjects (Polit \& Beck 2013). We obtained permission from the medical superintendents of the hospital to conduct this study. The ethical committee of Lincoln University College then gave permission to commence the research. Lastly, the Ministry of Health Sri Lanka gave the letter of approval to use the government hospitals to use patients for this research.

Written consent was explained to provide sufficient understanding of the study among patients who cannot understand English. Voluntary participation was encouraged among the selected patients.

\section{RESULTS AND FINDINGS}

Of the 150 adult obese patients it was identified that $76(50.7 \%)$ were the male and $74(49.3 \%)$ were female who were confined at the Ashraff Memorial Hospital in Kalmunai and Kalmunai Base Hospital, with increase cholesterol (Figure 1). The prevalence of these participants also identified the male gender to be more obese as compared with the females.
According to the study sample, participants' socio-economic statuses were identified under following characteristics such as education, economical status to be factors affecting increasing serum cholesterol among obese patients (Figure 2). Most of the participants were high in serum cholesterol level of the advanced education level of knowledge. Lower socio-economic participants were in low serum cholesterol level. Overall findings of low ordinary education attainment and lower socioeconomic patients were in low risk of serum cholesterol level.

Of the 150 obese patients admitted to medical wards and followed-up at medical clinics $59 \%$ were in moderate risk of serum cholesterol level, and 36\% were in high risk, and $2 \%$ were in minimal risk (Figure 3).

Table 1 identified that the age bracket of 30 to 40 years old obese Sri Lankan patients with a high probability $(p=0.061)$ correlated with cholesterol. Factors affecting cholesterol is more likely correlated with gender having the female $(p=0.026)$ to be higher than male $(p=0.025)$ even though men are more obese than women.

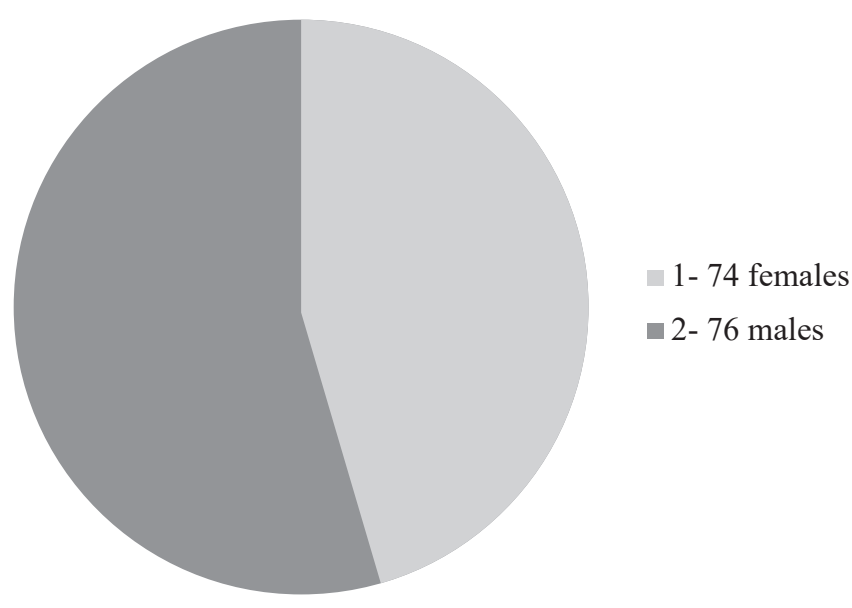

Figure 1. Gender factor affecting increase serum cholesterol level. 


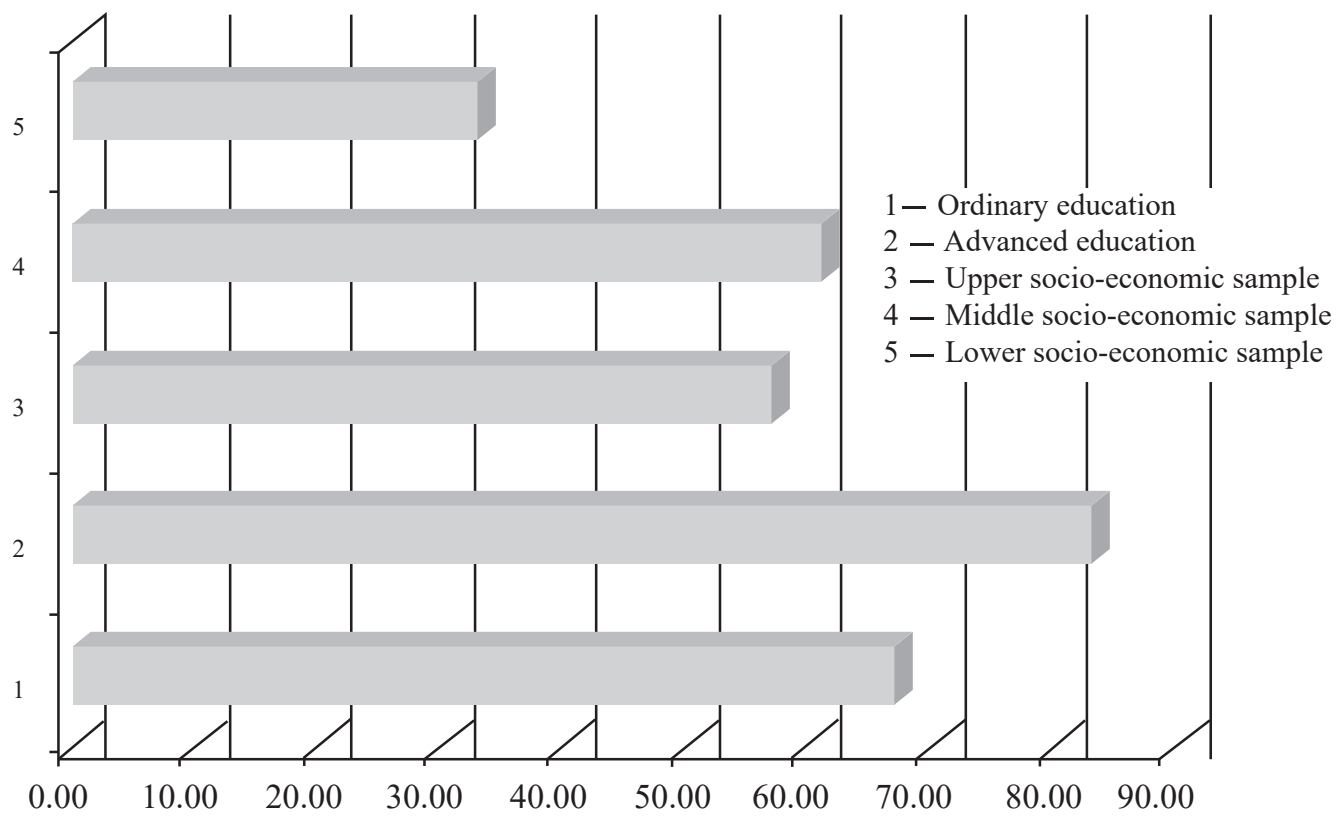

Figure 2. Socio-economic and educational demography.

Distribution of choloesterole level from the 150 subjects

$1 \square 2 \square 3 \square 4$

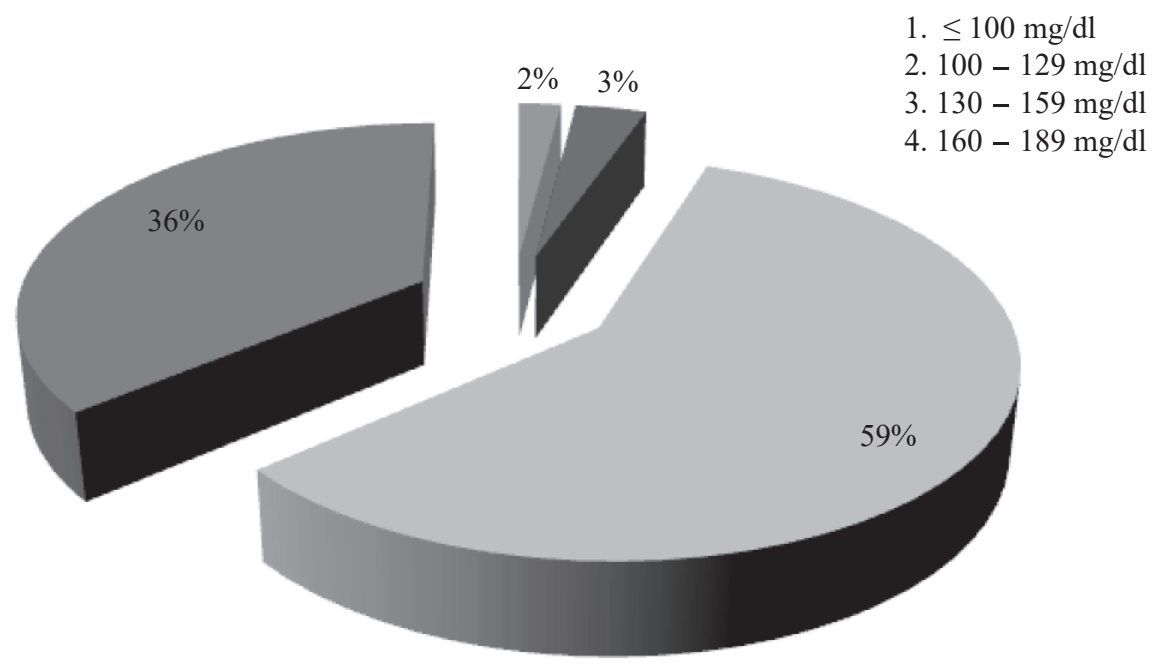

Figure 3. Serum cholesterol prevalence. 

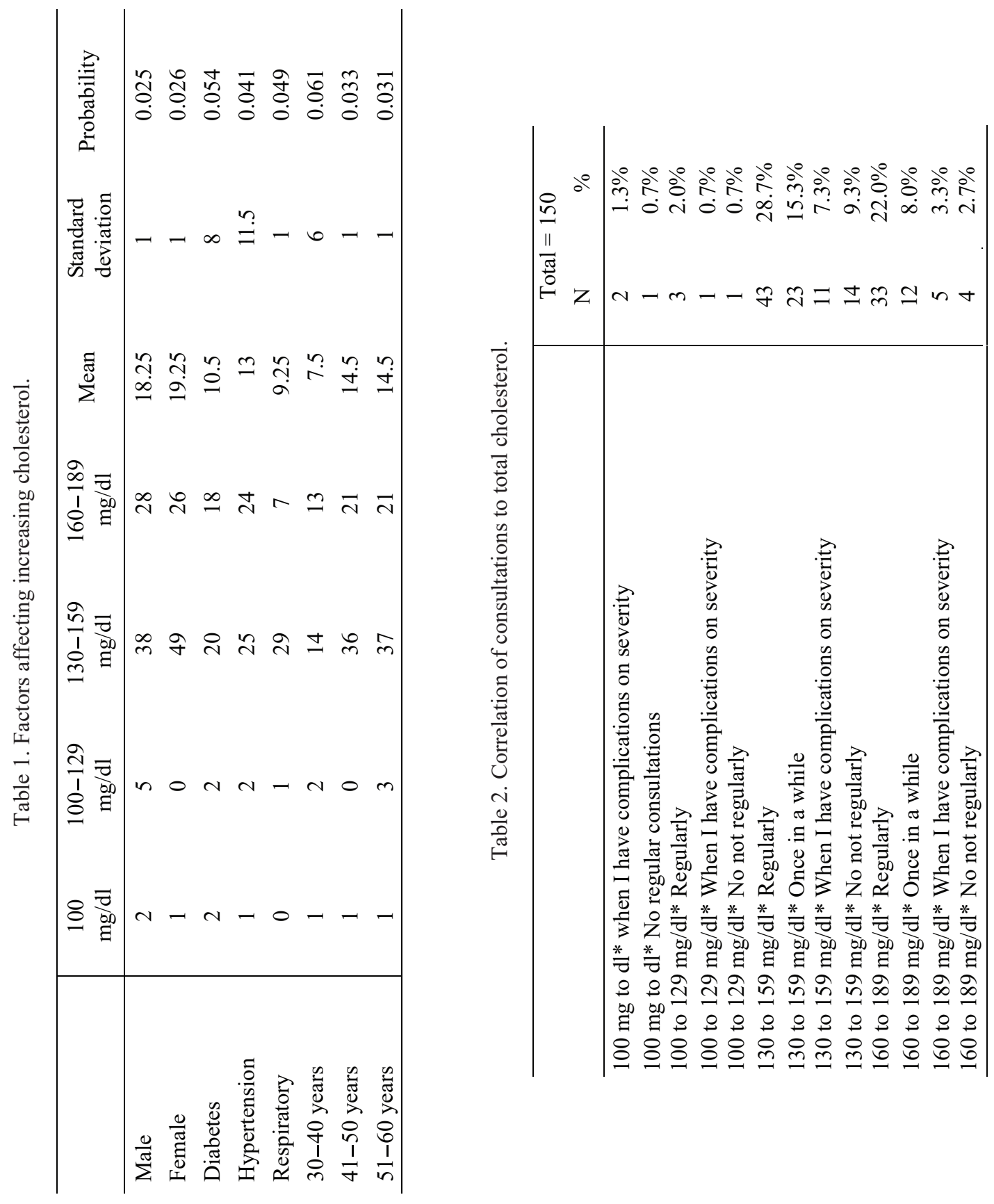
Co-morbidities of obesity such as diabetes mellitus $(\mathrm{p}=0.054)$, hypertension $(\mathrm{p}=0.041)$ and respiratory diseases $(\mathrm{p}=0.049)$ were identified as factors to affect an increase in serum cholesterol.

Gender was also identified as factors such as male $(p=0.025)$ and female $(p=0.026)$ but are not very likely among Sri Lankan adults to affect their cholesterol level.

The age bracket 41 to 50 years old $(p=0.033)$ was also identified to have affected increase cholesterol and are more probable as compared to the age bracket of 51 to 60 years of age $(p=0.031)$ to influence the increase in serum cholesterol.

Also it was investigated that correlations of cholesterol was due to consultations such as when patients had complications, if consultations were not regular and only once in a while, or if consultations were constantly done.

\section{CONCLUSION}

There was significant evidence of an increased serum cholesterol level among adult obese patients admitted to government hospitals in the eastern part of Sri Lanka.

Overall findings of 150 obese patients regarding increasing serum cholesterol level admitted in the medical wards and the followup at medical clinics had 59\% in moderate risk, $36 \%$ with high risk, and $2 \%$ with a minimal danger of increasing serum cholesterol level. About 74 (49.3\%) of the respondents were female, and $76(50.7 \%)$ were male. About 59\% had $130-159 \mathrm{mg} / \mathrm{dl}$ of total cholesterol level range while $36 \%$ had $160-189 \mathrm{mg} / \mathrm{dl}$, and $1 \%$ had lower than $100 \mathrm{mg} / \mathrm{dl}$ cholesterol level range. It was also identified that gender and co-morbidities affected an increasing serum cholesterol level including the age bracket of 41-50 and 51-60 years old.

\section{RECOMMENDATION}

For the Sri Lankan community, it was important to seek consultations more often. This is because most of the people in Sri Lanka were busy with their jobs and only sought consultations once co-morbidities of obesity occured with such symptoms of diabetes mellitus, hypertension, and respiratory disorders. If the practice of regular medical consultation was done, increasing serum cholesterol might be identified before symptoms of co-morbidities worsen.

Date of receipt: January 2017

Date of acceptance: June 2017

\section{ACKNOWLEDEMENT}

The authors would like to express our appreciation and gratitude to: the Ministry of Health of Sri Lanka; the Medical Superintendents of Ashraff Memorial Hospital and the Batticaloa Teaching Hospital of Sri Lanka; and the Ethical Committee of the Lincoln University College, for granting the permission to commence this study.

\section{REFERENCES}

Arai, T, Yamashita, S, Hirano, K-I, Sakai, N, Kotani, K, Fujioka, S, Nozaki, S, Keno, Y, Yamane, M, Shinohara, E, Waliul Islam, A H M, Ishigami, M, Nakamura, T, KamedaTakemura, T, Tokunaga, K, \& Matsuzawa, Y 1994, 'Increased plasma cholesterol ester transfer protein in obese subjects', Arterioscler Thromb, vol. 14, pp. 1129-1135. 
Basavanthappa, BJ 2005, Medical-surgical nursing, Jaypee Brothers. New Delhi, India.

Burns, N \& Grove, SK 2007, Understanding nursing resaerch, Arlington, Texas, Saunders.

Cordelia, B \& Milliard, G 1995, 'Serum cholesterol and perception on anger and sadness', <http://www.serum choles.com/ volume $77 /$ number $1343-1345 /$ article $>$.

Hill, JO \& Peters, JC 2010, 'Environmental contributions to obesity epidemic', Science Journal, vol. 2, no. 80, pp. 25-31.

JAMA 1985, Lowering blood cholesterol to prevent heart disease, Office of Medicine Application Research, National Institutes of Health, 253:2080-6
Polit, DF \& Beck, CT 2013, Essentials of nursing research, 9th edn Lippincott, New York.

Roberta, E, Donna, R \& Charles, G 2006, Patients 'perceptions of cholesterol, cardio Vascular disease and risk communication, $<$ http://www.serum choles.com/number 205-212>.

Turley, SD \& Dietschy JM 1988, The metabolism and excretion of cholesterol by the liver, in the liver; biology and pathology, ed IM Arias, Raven Press, N.Y.

Turnock, BJ 2004, 2001, Public health, what it is and how it works, 3rd edn, BT Basavanthappa, Illinosis, Chicago, and Nursing research, Chennai, Jaypee Brothers, India. 